\title{
Development and Evaluation of Palm-based Tibetan Butter Equivalent: Formulation, Rheology, Texture and Microstructure
}

\author{
Chuan-Guo $\mathrm{Ma}^{1}$, Jie-Yu Li ${ }^{1}$, Min $\mathrm{Ji}^{2}$, Yoong Jun $\mathrm{Hao}^{2}$, and Xiao-Wei Chen ${ }^{1}$ \\ ${ }^{1}$ Henan University of Technology \\ ${ }^{2}$ Palm Oil Research and Technical Service Institute of MPOB
}

July 16, 2021

\begin{abstract}
Palm-based Tibetan butter equivalent was developed and evaluated from formulation, rheology, texture to microstructure. Firstly, the compatibility of palm stearin and palm olein was ascertained. The formulations of palm-based Tibetan butter equivalent were then optimally developed using a combination of palm stearin (37.5\%), palm olein (37.5\%) and soybean oil (25\%). These were found to contain high unsaturated fatty acids and analogous solid fat content (SFC) at varying temperatures. Moreover, the palm-based Tibetan butter equivalent (TBE) showed a shear-thinning behavior, a gel characteristic, good plasticity and comparable texture characteristics (such as hardness, adhesion, cohesiveness and elasticity) to traditional Tibetan butter (TB). Furthermore, as determined by polarized light microscopy (PLM) and confocal laser scanning microscopy (CLSM), the microstructures also showed a similar structure, thus further indicating that palm oil is a good candidate as a substitute in making Tibetan-style butter. Overall, the palm-based Tibetan butter equivalent was developed by physical technology and could assist in increasing the enjoyable population as well as addressing the challenge of resource shortage, geographical origin and season of production.
\end{abstract}

\section{Hosted file}

Manuscripts.doc available at https://authorea.com/users/425995/articles/530649-developmentand-evaluation-of-palm-based-tibetan-butter-equivalent-formulation-rheology-texture-andmicrostructure 